\title{
Clinical utility gene card for: Peters plus syndrome
}

\author{
Jaak Jaeken ${ }^{\star, 1}$, Dirk J Lefeber ${ }^{2}$ and Gert Matthijs ${ }^{3}$ \\ European Journal of Human Genetics (2016) 24, doi:10.1038/ejhg.2016.32; published online 6 April 2016
}

\section{DISEASE CHARACTERISTICS}

1.1 Name of the disease (synonyms)

Deficiency of beta-1,3-galactosyltransferase-like, Peters-plus syndrome, Peters' plus syndrome, Peters'-plus syndrome, Krause-Kivlin syndrome, Krause-van Schooneveld-Kivlin syndrome, B3GALTL deficiency, B3GLCT defect, B3GALTL defective congenital disorder of glycosylation, B3GALTL-CDG, O-fucose-specific $\beta$-1,3-glucosyltransferase deficiency.

\subsection{OMIM\# of the disease \\ 261540 .}

1.3 Name of the analysed genes or DNA/chromosome segments B3GALTL.

\subsection{OMIM\# of the gene(s)}

610308 .

\subsection{Mutational spectrum}

Fourteen variants that affect function have been reported, including 6 splicing variants, 4 nonsense variants, 3 missense variants, 1 frameshift variant, as well as 3 large deletions. The c. $660+1 \mathrm{G}>\mathrm{A}$ splicing variant is the most common variant identified. It accounts for $69 \%$ of all reported pathogenic alleles. ${ }^{1}$ (www.lovd.nl/B3GALTL). The standard reference sequence indicating reported variants (ENSG00000187676) and a reference for exon numbering (ENST00000461652) can be found at http://www.ensembl.org.

\subsection{Analytical methods}

Sanger sequencing of the fifteen coding exons and flanking intronic sequences of the B3GALTL gene (NCBI reference sequence: NM_194318.3).

\subsection{Analytical validation}

Sanger sequencing identifies variants in $>99 \%$ of patients. Deep intronic variants, large deletions and duplications would not be detected using this approach. Novel variants with uncertain pathogenic nature are of course possible.

\subsection{Estimated frequency of the disease}

(incidence at birth ('birth prevalence') or population prevalence. If known to be a variable between ethnic groups, please report):

The total number of reported patients with Peters plus syndrome due to B3GALTL variants is 49 (belonging to
40 families). ${ }^{1-3}$ The frequency and the prevalence of the disease are not known.

\subsection{Diagnostic setting}

\begin{tabular}{lll}
\hline & Yes & No \\
A. (Differential) diagnostics & $\bigotimes$ & $\square$ \\
B. Predictive testing & & \\
C. Risk assessment in relatives & $\bigotimes$ & $\square$ \\
D. Prenatal & $\bigotimes$ & $\square$ \\
\hline
\end{tabular}

Comment:

The term 'Peters'-plus syndrome' was first proposed in 1984 by van Schooneveld et al. ${ }^{4}$ The underlying defect (mutations in B3GALTL coding for O-fucose-specific $\beta$-1,3-glucosyltransferase) was identified in 2006. ${ }^{5-7}$ B3GALTL is involved in the synthesis of the unusual O-linked disaccharide glucosyl-beta-1,3-fucose-O- attached to the thrombospondin type 1 repeats (TSRs) of many important proteins. The biosynthesis of this disaccharide is initiated by proteinO-fucosyltransferase 2, which attaches the fucosyl residue to a serine or threonine within the TSR. B3GALTL subsequently transfers the glucose onto TSR-fucose. This disorder thus belongs to the protein O-glycosylation defects, subgroup O-fucosylglycan synthesis defects. Peters plus syndrome due to defective B3GALTL is an autosomal recessive disorder. Constant features are anterior chamber eye abnormalities and rhizomelic limb shortening. The most common anterior chamber eye defect is Peters' anomaly. It comprises central corneal clouding, thinning of the posterior cornea and iridocorneal adhesions, and is usually bilateral. Its expression ranges from mild to severe. Lens abnormalities (cataracts, congenital glaucoma) are associated with the severe form. Growth retardation starts prenatally, and in some patients there is also growth hormone deficiency that responds well to growth hormone treatment. In the majority of patients, there is variable developmental delay/intellectual disability, as well as craniofacial dysmorphism (variable combinations of a prominent forehead, a broad neck, short palpebral fissures, a long filtrum, an exaggerated Cupid's bow of the vermilion of the upper lip, a cleft lip, a cleft palate and ear anomalies). Less frequent findings are brain, heart and urogenital malformations. A few patients have been reported with congenital hypothyroidism or conductive hearing loss. No phenotypegenotype correlation could be found. No biochemical markers have been identified; serum apo C-III and serum transferrin

${ }^{1}$ Centre for Metabolic Disease, Department of Pediatrics, University Hospital Gasthuisberg, KU Leuven, Leuven, Belgium; ${ }^{2}$ Department of Neurology, Translational Metabolic Laboratory, Radboudumc, Nijmegen, The Netherlands; ${ }^{3}$ Centre for Human Genetics, KU Leuven, Leuven, Belgium

${ }^{*}$ Correspondence: Professor J Jaeken, Centre for Metabolic Disease, Department of Pediatrics, University Hospital Gasthuisberg, KU Leuven, Herestraat 49, BE 3000, Leuven, Belgium. Tel: +32 16 343827; Fax: +32 16 343842; E-mail: jaak.jaeken@med.kuleuven.be

Received 23 December 2015; revised 27 January 2016; accepted 1 February 2016; published online 6 April 2016 
isoelectrofocusing show a normal pattern. The diagnosis has to be confirmed by mutation analysis of B3GALTL. No B3GALTL mutations have been found in Peters plus syndrome-like phenotypes or in isolated Peters' anomaly. An upcoming strategy, in case of clinical suspicion of Peters plus syndrome, is to subject the DNA to a panel of genes known to be involved in CDG. The identification of the pathogenic variant(s) will permit heterozygote detection in the family and prenatal diagnosis.

\section{TEST CHARACTERISTICS}

\begin{tabular}{|c|c|c|c|c|}
\hline & \multicolumn{2}{|c|}{ Genotype or disease } & \multirow{2}{*}{$\begin{array}{l}\text { A: True positives } \\
\text { B: False positives }\end{array}$} & \multirow{2}{*}{$\begin{array}{l}\text { C: False negative } \\
\text { D: True negative }\end{array}$} \\
\hline & Present & Absent & & \\
\hline \multicolumn{5}{|l|}{ Test } \\
\hline Positive & A & B & $\begin{array}{l}\text { Sensitivity: } \\
\text { Specificity: }\end{array}$ & $\begin{array}{l}A /(A+C) \\
D /(D+B)\end{array}$ \\
\hline Negative & C & $\mathrm{D}$ & $\begin{array}{l}\text { Positive predictive value: } \\
\text { Negative predictive value: }\end{array}$ & $\begin{array}{l}A /(A+B) \\
D /(C+D)\end{array}$ \\
\hline
\end{tabular}

\subsection{Analytical sensitivity}

(proportion of positive tests if the genotype is present)

There is no other test to confirm the diagnosis in a patient than molecular genetic testing.

\subsection{Analytical specificity}

(proportion of negative tests if the genotype is not present)

See 2.1.

\subsection{Clinical sensitivity}

(proportion of positive tests if the disease is present)

The clinical sensitivity can be dependent on variable factors such as age or family history. In such cases, a general statement should be given, even if a quantification can only be made case-by-case.

The proportion of B3GALTL mutations is close to $100 \%$ in patients with classic Peters plus syndrome.

\subsection{Clinical specificity}

(proportion of negative tests if the disease is not present)

The clinical specificity can be dependent on variable factors such as age or family history. In such cases, a general statement should be given, even if a quantification can only be made case-by-case.

In the absence of classic Peters plus syndrome, the proportion of B3GALTL mutations is nearly $0 \%$.

\subsection{Positive clinical predictive value}

(life time risk to develop the disease if the test is positive)

$100 \%$, based on the presence of B3GALTL mutations.

2.6 Negative clinical predictive value

(probability not to develop the disease if the test is negative)

Assume an increased risk based on family history for a non-affected

person. Allelic and locus heterogeneity may need to be considered.

Index case in that family had been tested:

$100 \%$.

Index case in that family had not been tested:

$100 \%$.

\section{CLINICAL UTILITY}

3.1 (Differential) diagnostics: The tested person is clinically affected (To be answered if in 1.9 'A' was marked)

3.1.1 Can a diagnosis be made other than through a genetic test?

\begin{tabular}{ll}
\hline No & $\bigotimes$ (continue with 3.1.4) \\
Yes & Clinically \\
& Imaging \\
& Endoscopy \\
& Biochemistry \\
& Electrophysiology \\
& Other (please describe)
\end{tabular}

3.1.2 Describe the burden of alternative diagnostic methods to the patient

Not applicable.

3.1.3 How is the cost effectiveness of alternative diagnostic methods to be judged?

Not applicable.

3.1.4 Will disease management be influenced by the result of a genetic test?

\begin{tabular}{|c|c|c|}
\hline No & \multicolumn{2}{|c|}{$\square$} \\
\hline Yes & $\otimes$ & \\
\hline & $\begin{array}{l}\text { Therapy } \\
\text { (please describe) }\end{array}$ & $\begin{array}{l}\text { Preservation of vision often requires surgery: corneal } \\
\text { transplantation (penetrating keratoplasty) or, in mild } \\
\text { cases, separation of iridocorneal adhesions. }\end{array}$ \\
\hline & $\begin{array}{l}\text { Prognosis } \\
\text { (please describe) }\end{array}$ & $\begin{array}{l}\text { Many children with penetrating keratoplasty for the less } \\
\text { severe forms of Peters' anomaly can experience good or } \\
\text { functional vision in their operated eye. Treatment of } \\
\text { glaucoma shows satisfactory results only in a minority of } \\
\text { patients. }^{8}\end{array}$ \\
\hline & $\begin{array}{l}\text { Management } \\
\text { (please describe) }\end{array}$ & $\begin{array}{l}\text { B3GALTL-CDG is a multi-system disease requiring a } \\
\text { multidisciplinary follow-up particularly of the eye anomalies }\end{array}$ \\
\hline
\end{tabular}

3.2 Predictive setting: The tested person is clinically unaffected but carries an increased risk based on family history

(To be answered if in 1.9 ' $\mathrm{B}$ ' was marked)

3.2.1 Will the result of a genetic test influence lifestyle and prevention?

If the test result is positive (please describe):

Not applicable.

If the test result is negative (please describe):

Not applicable.

3.2.2 Which options in view of lifestyle and prevention does a person at-risk have if no genetic test has been done (please describe)?

Not applicable.

3.3 Genetic risk assessment in family members of a diseased person (To be answered if in $1.9^{\text {'C }}$ ' was marked)

3.3.1 Does the result of a genetic test resolve the genetic situation in that family?

Usually yes, by testing the potential heterozygous persons (carriers) in the family. 
3.3.2 Can a genetic test in the index patient save genetic or other tests in family members?

No.

3.3.3 Does a positive genetic test result in the index patient enable a predictive test in a family member?

Not applicable.

\subsection{Prenatal diagnosis}

(To be answered if in 1.9 ' $\mathrm{D}$ ' was marked)

3.4.1 Does a positive genetic test result in the index patient enable a prenatal diagnosis?

Yes. Prenatal diagnosis is possible by molecular analysis.

\section{IF APPLICABLE, FURTHER CONSEQUENCES OF TESTING}

Please assume that the result of a genetic test has no immediate medical consequences. Is there any evidence that a genetic test is nevertheless useful for the patient or his/her relatives? (Please describe)

Knowledge of the diagnosis will stop unnecessary further investigations, and will help the parents in the process of accepting the disease although no curative treatment is available.

\section{CONFLICT OF INTEREST}

The authors declare no conflict of interest.

\section{ACKNOWLEDGEMENTS}

This work was supported by EuroGentest2 (Unit 2: 'Genetic testing as part of health care'), a Coordination Action under FP7 (Grant Agreement Number 261469) and the European Society of Human Genetics.

1 PLesnik Oberstein SAJ, van Belzen M, Hennekam R: Peters plus syndrome. In: Pagon RA, Adam MP, Ardinger HH et al (eds): Gene Reviews (Internet). Seattle, WA, USA: University of Washington, Seattle, 2007 (updated 23 Jan 2014).

2 Gupta N, Kaul A, Kabra M: Prenatal diagnosis of Peters' plus syndrome: a case report. Case Rep Genet 2013; 2013: 364529.

3 Weh E, Reis LM, Tyler RC et al: Novel B3GALTL mutations in classic Peters plus syndrome and lack of mutations in a large cohort of patients with similar phenotypes. Clin Genet 2014; 86: 142-148.

4 van Schooneveld MJ, Delleman JW, Beemer FA et al: Peters'-plus: a new syndrome. Ophthalmic Paediatr Genet 1984; 4: 141-145.

5 Kozma K, Keusch JJ, Hegemann B et al: Identification and characterization of a $\beta 1$, 3 -glucosyltransferase that synthesizes the Glc- $\beta 1,3-F u c$ disaccharide on thrombospondin type 1 repeats. J Biol Chem 2006; 281: 36742-36751.

6 Lesnik Oberstein SA, Kriek M, White SJ et al: Peters plus syndrome is caused by mutations in B3GALTL, a putative glycosyltransferase. Am J Hum Genet 2006; 79: 562-566.

7 Sato T, Sato M, Kiyohara $\mathrm{K}$ et al: Molecular cloning and characterization of a novel human beta 1,3-glucosyltransferase which is localized at the endoplasmic reticulum and glucosylates O-linked fucosylglycan on thrombospondin type 1 repeat domain. Glycobiology 2006; 16: 1194-1206.

8 Zaidman GW, Flanagan JK, Furey CC: Long-term visual prognosis in children after corneal transplant surgery for Peters anomaly type I. Am J Ophthalmol 2007; 144: 104-108. 